\title{
Simulation OF Quarter Car Model
}

\author{
Priti Tiwari ${ }^{1}$, Dr.G.R.Mishra ${ }^{2}$ \\ ${ }^{I}$ Department of Electronics \& Communication Engineering, Amity School of Engineering \& Technology Amity \\ University Uttar Pradesh, Lucknow Campus, India) \\ ${ }^{2}$ Department of Electronics \& Communication Engineering, Amity School of Engineering \& Technology Amity \\ University Uttar Pradesh, Lucknow Campus, India
}

\begin{abstract}
The automobile suspension's design incorporates three conflict criteria's which are road handling, load carrying and passenger comfort. All these suspensions systems are generally require maintaining vehicle stability by reducing the effect of dynamic loads. The response of system is simulated by using the software "Symbol's Shakti". The bond graph model of the system with active and passive suspension is simulated at various operating speed was the fourth order runge-kutte method. The concept of using an active suspension system for vehicle is to provide the best performance of car controlling. The basic purpose of a fully active suspension system is to control the suspension over the full bandwidth of the system. the introduction of the different types of suspension system such as passive, semi-active, active suspension system. The physical and mathematical modeling for quarter car model with suspension system is presents.
\end{abstract}

Keywords: Car models, Bond graph modelling, Dynamic behaviour, Active suspension system, Passive suspension systems, Comfort evaluation About five key words in alphabetical order, separated by comma.

\section{INTRODUCTION}

Suspension systems are designed to maintain vehicle stability by reducing the effects of dynamic loads while providing a comfortable ride via the reduction of impulse forces from terrain features. Suspension system is mechanism that physically separates the car body from the car wheel. The primary function of a suspension system is to minimize acceleration inputs to a vehicle. Ride comfort is one of the most critical factors to evaluate the vehicle performance. There are generally two procedures to evaluate the ride comfort of a vehicle, i.e. computer simulation and road experiment. Computer simulation method is based on the mathematical model of the vehicle vibration. Simulation programs can be effectively used to extrapolate the experiment results over the range of test conditions Suspension systems originally came to use in horse-drawn carriages.

The suspension system is of three types: Passive suspension, Semi-Active suspension and Active suspension.

\subsection{PASSIVE SUSPENSION}

The passive system is the most used type in automobile suspensions. A spring and a damper compose this suspension system, fixed between the wheel supporting (unsprung mass) \& the vehicle body (sprung mass). For passive suspension, reducing effects of impulse forces requires the use of soft springs and moderate to low damping rates, while reducing the effects of dynamic forces requires the use of stiff springs and high damping rates. The component selection for the design of a passive suspension represents a trade between ride comfort and dynamic performance.

\subsection{SEMI-ACTIVE SUSPENSION}

Semi-active suspensions are similar to passive suspensions except they possess variable damping rates. There are three categories of variable damping mechanisms including hydraulic, friction, and magnetorheological (MR). The time delay associated with hydraulic and friction systems make them a poor choice for use in semi-active suspension systems. Magneto-rheological dampers have shown to be among the most promising components for use in semi-active suspension systems due to their quick response times which result from the absence of electromechanical actuators.

\subsection{ACTIVE SUSPENSION}

The vibration suppression capabilities of the traditional passive and semi-active suspension systems are restricted, active suspension system with additional control force to suppress the oscillations is one of the major development fields in recent vehicle industry. Fully active suspension system use hydraulic actuator which creates the desired force in the suspension system. The actuator may be in parallel with a passive spring. Both the semi-active and fully active suspensions require sensors to be located on the vehicle which measure suspension variables. Fully active suspensions can consume large amounts of power to provide the control forces. In the active suspension system, the force actuator is able to add \& dissipate energy from the system. 
This results in the capability of suspension system to control the attitude of the vehicle, to reduce the braking effect and to reduce the vehicle roll during cornering and braking in addition to increasing the ride comfort and vehicle handling.

\section{PhySiCAL MODEL OF VEHICLE}

QUARTER CAR MODEL - It is combination of one wheel and has two degree of freedom. It is shown in figure 2.1.

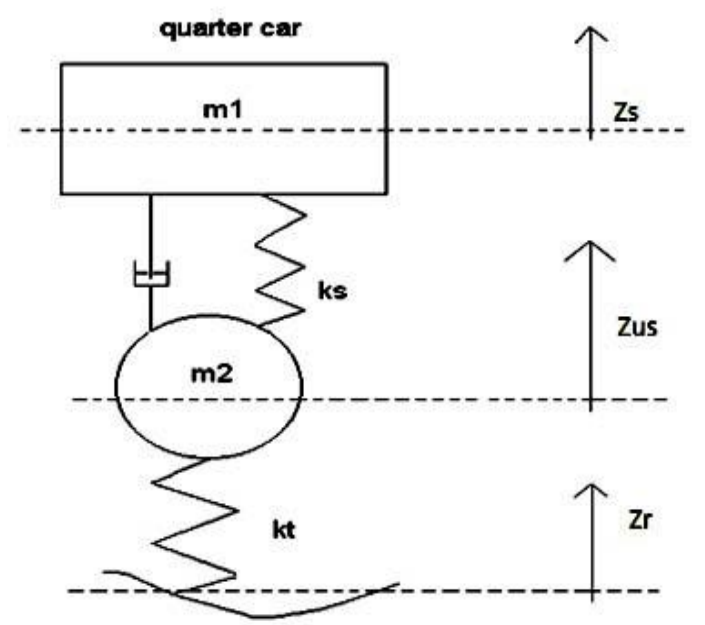

Figure2.1. Physical Model of Quarter Car Model

\subsection{WITHOUT CONTROLLER}

\section{BOND GRAPH MODELLING}

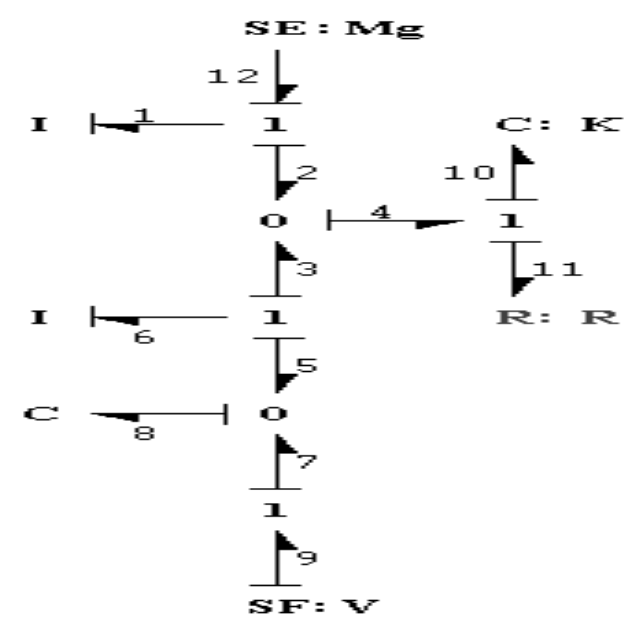

Figure.3.1 Bond graph model of Quarter Car Model

\subsection{WITH CONTROLLER-PID}




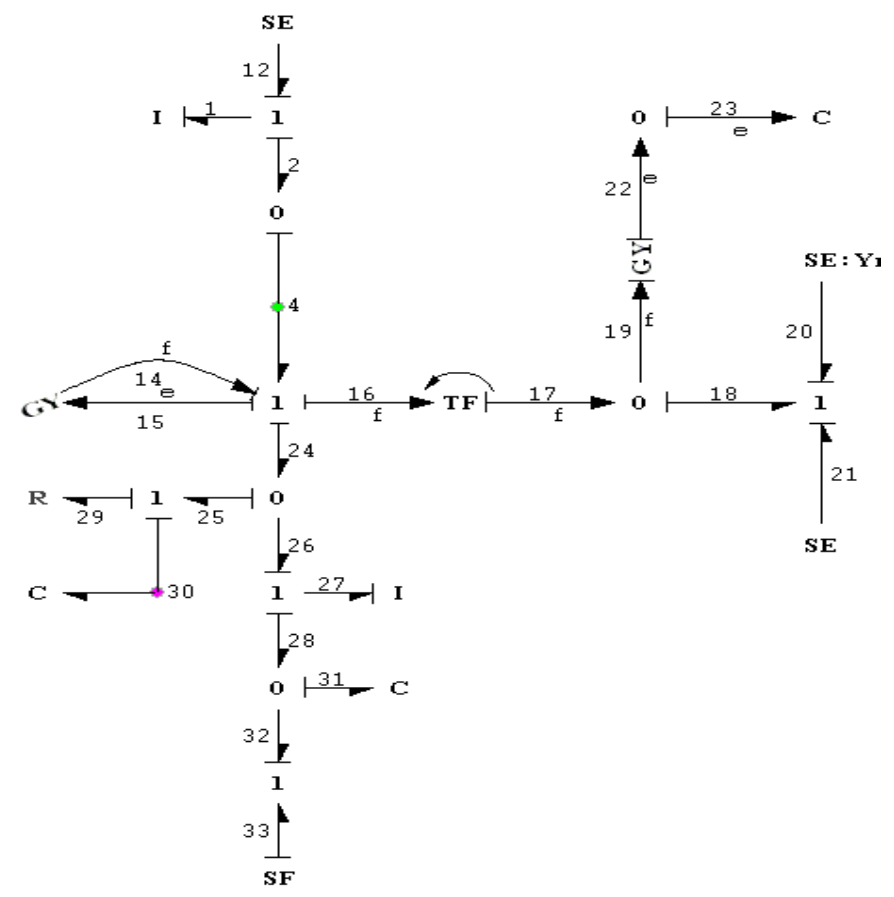

Figure.3.2 Bond graph model of Quarter Car Model with PID

IV. SIMULATION

It is a representation of reality through use of model under a given sets of conditions

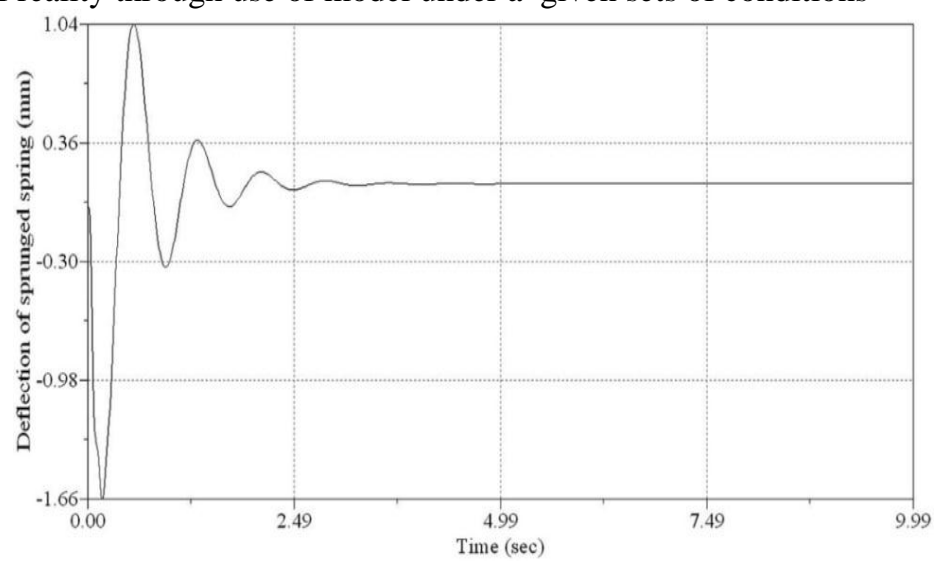

Figure.4.1 Deflection of sprunged spring for quarter car

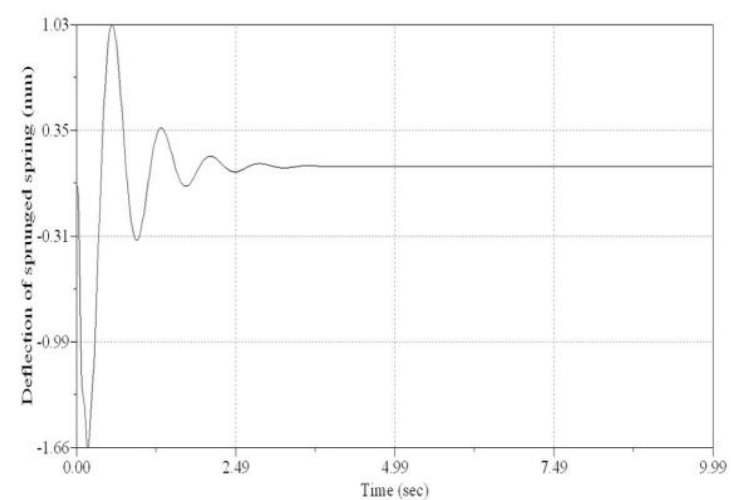

Figure.4.2. Deflection of sprunged spring with PID controller for quarter car 
V. SIMULATION PARAMETERS

Table 1. Quarter car parameter

\begin{tabular}{|c|c|c|c|}
\hline S.No & Item & Value & Unit \\
\hline 1 & Body Mass $\left(\mathrm{M}_{\mathrm{s}}\right)$ & 250 & $\mathrm{Kg}$ \\
\hline 2 & Wheel Mass $\left(\mathrm{M}_{\mathrm{us}}\right)$ & 50 & $\mathrm{Kg}$ \\
\hline 3 & Stiffness of Body $\left(\mathrm{K}_{\mathrm{s}}\right)$ & 18.6 & $\mathrm{KN} / \mathrm{m}$ \\
\hline 4 & Stiffness of Wheel $\left(\mathrm{K}_{\mathrm{t}}\right)$ & 19.6 & $\mathrm{KN} / \mathrm{m}$ \\
\hline 5 & Damping Coefficient $\left(\mathrm{C}_{\mathrm{s}}\right)$ & 1.0 & $\mathrm{KNs} / \mathrm{m}$ \\
\hline
\end{tabular}

Table 2.Controller's Gain

\begin{tabular}{|c|c|c|}
\hline \multicolumn{3}{|c|}{ Table 2.Controller's Gain } \\
\hline S.No & Items & Value \\
\hline 1. & Proportional gain(Gp) & 0.9 \\
\hline 2. & Integral gain(Ip) & 0.0225 \\
\hline 3. & Derivative gain(Pd) & 4.5 \\
\hline
\end{tabular}

\section{RESULT}

This paper has been attempted to obtain the dynamic behaviour of car through bond graph technique and to evaluate the different parameters through simulation at various speeds. The data of comfort may be compared with the available study on this subject matter and show a considerable agreement. Moreover, these values changed in difficult environment conditions. However, the following conclusions are made in this paper present in next sub section.

- The dynamic model of car had been constructed through bond graph technique.

- The model of controller-suspension contact dynamics had been constructed by using bond graph technique.

- $2 \mathrm{DOF}, 4 \mathrm{DOF}$ and 7DOF model is used for the analysis.

- Minimum wheel deflection for better handling performance and minimum vertical car body velocity for ride comfort have been achieved in terms of low overshoot and settling time which is complimented by simulation results.

\section{REFERENCES}

[1] Yagiz, N., Hacioglu, Y., Backstepping control of vehicle with Passive suspensions Control Engineering Practice, 2-11, 2008.

[2] Sun, L., Optimum design of 'road-friendly' vehicle suspension systems subjected to rough pavemen surfaces, Applied Mathematical Modeling, 26, 635- 652,2002

[3] Sireteanu, T., Stoia, N., Damping optimization of passive and semi-active vehicle suspension by numerical simulation, Proceedings of the Romanian Academy, 2003.

[4] Miller L.R (1988), "Tuning passive, semi-active, and fully active suspension systems,” In Proc.27th IEEE conference on Decision and Control, vol. 3, pp. 2047-2053,

[5] Mouleeswaran S. K. (2008) "Development of active suspension system for automobiles using PID controller," Proceedings of the World Congress on Engineering, London, U.K. 